\section{Comment on: Patterns of cervical spine injuries in adults at a major trauma center in Saudi Arabia}

\section{To the Editor}

In a study about cervical spine injuries, Dr. Alharbi described the patterns of cervical spine injuries affecting adults in a major trauma center in Riyadh, Saudi Arabia. ${ }^{1}$ This retrospective collaborative study comprised adults with cervical spine injuries from 2014 to 2018, excluding patients 13 years of age and below. However, as per the United States Food and Drug Administration Class III classification, the adolescent age group is up to 18 years of age, ${ }^{2}$ whereas the skeletal maturation is more advanced in girls than boys of the same age because the early pubertal bone ages of 11 years old girls and 13 years old boys are equivalent stages of bone maturation by the hand-wrist method. ${ }^{3}$ Accordingly, the exclusion of pediatric age 13 years and below was somehow vague, whether based on institutional level or a specifically followed classification of pediatric age.

Studies that focus on cervical spine injuries usually consider including more accurate imaging modalities as magnetic resonance imaging (MRI) to not miss patients with normal computerized tomography (CT) scans. In a study conducted by Holmes et $\mathrm{al}^{4}$ to describe the performance of adjunctive radiologic imaging in patients with a cervical spine injury, it was found that most patients with cervical spine injury undergo MRI or CT imaging. However, in clinical practice, MRI is superior at identifying soft tissue injuries, whereas CT performs better in identifying bony injuries. Accordingly, the current study only included CT that was abnormal excluding patients with normal CT. This might disregard clinical situations that could indicate cervical injures diagnosed on superior imaging modality as MRI.

Limited literature is available on our local experience regarding the patterns of cervical spine injuries. And it is noteworthy that motor vehicle accidents were the most frequent causative of injury (92.6\%) which was higher than the international reports (25-50\%). Therefore, additional emphasis on the seat position of passengers and the differences of vehicles could yield more accurate results, availing a clear understanding of the patterns of injures. Two retrospective studies comparing motorcycle trauma with all-terrain vehicles trauma have shown similar mortality. All-terrain vehicles riders were found to be significantly younger and more severely injured with a higher incidence of head and neck injury (56\% vs. $30 \%, p<0.001) .^{5}$ Another article evaluated the differences in injury patterns according to seat position: i) Victims who were front seated passengers had the highest mortality. ii) Rear seat passengers were found to be at greater risk for serious traumatic brain injuries (BTIs). ${ }^{6}$ This pattern of injuries correlated with TBIs, which was in the current study addressed solely with Glasgow coma scale (GCS) scores. Contrarily, Chieregato et $\mathrm{al}^{7}$ found a consensus of Italian anesthetists with the classification of TBI severity that includes CT findings and pupil reactivity besides GCS scores. In another study, conducted by Malec et $\mathrm{al}^{8}{ }^{8}$ a single TBI severity classification system based on commonly used TBI severity measures was developed. This system classified TBI according to death due to TBI, traumarelated neuroimaging abnormalities, GCS, PTA, loss of consciousness, and specified post-concussive symptoms. For the moderate-severe (definite) TBI classification, the estimated sensitivity was $89 \%$ and the estimated specificity was $98 \% .{ }^{8}$ This highlights the importance of the details associated with this kind of injury to reach to a more accurate description of the patterns of cervical spinal injuries, especially in our local population.

\section{Abdulrabman Albabkley Rouaa Mandurah Department of Physical Medicine and Rehabilitation King Fahad Medical City Riyadh, Kingdom of Saudi Arabia}

Saudi Med J 2021; Vol. 42 (2): 232-233 doi: 10.15537/smj.2021.42.2.20210003

\section{Reply from the Author}

We would like to thank Dr. Abdulrahman Bahkley for his interest and valuable commentary on our study entitled, "Patterns of cervical spine injuries in adults at a major trauma center in Saudi Arabia" published in Saudi Medical Journal, November $2020{ }^{1}$

In Saudi Arabia, as per the Saudi Health Council, the upper limit for the age group in children was set at 14 years. The decision has been implemented in all regions and governorates of the country. As a result, data from adult hospitals include patients who are $\geq 14$ years. To make our data useful in comparing it to other published data, we separated our data based on age group.

Our aim in the study was to provide epidemiological data about traumatic cervical spine injuries in a 
representative major trauma center. Patients with such injuries undergo CT scans which are more suitable in the emergency room (ER) to identify such injuries in emergency settings. Our main focus was to describe the patterns of cervical spine (not only spinal cord) injuries, in terms of the involved cervical spine levels, number of involved levels, and anatomical location of possible fractures. Magnetic resonance imaging is plainly less sensitive for such bony injuries. It is indeed more superior for suspected spinal cord or ligamentous injuries. ${ }^{9}$ Therefore, not all patients underwent subsequent MRI.

We agree that the severity of head injury can be determined by multiple parameters. However, classification systems that collect multiple parameters like "The Mayo Classification System" determine the outcome of head injury and guide in planning the post-acute clinical care. Glasgow Coma Score is a well-established clinical score used as a predictor and not a determinant of the outcome of head injury especially in emergency settings. ${ }^{10}$ The use of GCS is limited in sedated and intubated patients; therefore, other parameters are added in such conditions. In our study, we reported the GCS upon arrival to the ER as an early predictor of clinical outcome in patients with associated head injury evident on brain CT scans.

We totally agree that motor vehicle accidents (MVA) are a major health concern in Saudi Arabia. Reporting the use of seat belt, seat position, and type of motor vehicles would yield more accurate results. We hope that our results are used as a reference for future reports, advocate for implementing more preventive measures, and contribute to building community-based programs on this major health issue in our community. Alnaami et $\mathrm{al}^{11}$ retrospectively investigated the epidemiological aspects of traumatic brain injuries in Saudi Arabia. In their study, MVA accounted for the majority of head injuries in spite of the implementation of traffic rules. ${ }^{11}$ The authors advocated the importance of assessing traumatic brain injury after the implementation of new governmental rules and regulations, namely, forced seat belt wearing and probation of cell phone usage while driving. ${ }^{11}$ Additionally, Al-Habib et al ${ }^{12}$ retrospectively reviewed the descriptive features of traumatic brain injury in Saudi Arabia. Similar to the previous studies, road traffic accidents, followed by pedestrian injuries, were the most frequent causes of hospitalization as well as injury-related mortality. ${ }^{12}$ Our results highlighted the importance of developing educational programs, for neurotrauma prevention, to be utilized as a blueprint for the local hospitals and officials in Saudi Arabia.

\section{References}

1. A Alharbi A, Alkhaibary A, Aloraidi A, Alwohaibi M, Alkhani A. Patterns of cervical spine injuries in adults at a major trauma center in Saudi Arabia. Saudi Med J 2020; 41: 1259-1262.

2. U.S. Food \& Drug Administration. Guidance DocumentGeneral Considerations for Pediatric Pharmacokinetic Studies for Drugs and Biological Products. [Updated 2014. Accessed 2021 January 2]. Available from URL: https:/www.fda.gov/ regulatory-information/search-fda-guidance-documents/ general-clinical-pharmacology-considerations-pediatricstudies-drugs-and-biological-products

3. Alison Middleditch. Chapter 10 - Physiotherapy and occupational therapy in the hypermobile adolescent. In: Hakim AJ, Keer R, Grahame R. Hypermobility, Fibromyalgia and Chronic Pain. London: Churchill Livingstone; 2010. p. 163-177.

4. Holmes JF, Mirvis SE, Panacek EA, Hoffman JR, Mower WR, Velmahos GC; NEXUS Group. Variability in computed tomography and magnetic resonance imaging in patients with cervical spine injuries. J Trauma 2002; 53: 524-529; discussion 530.

5. Concannon E, Hogan A, Lowery A, Ryan RS, KhanW, Barry S. Spectrum of all-terrain vehicle injuries in adults: A case series and review of the literature. Int J Surg Case Rep 2012; 3: 222-226.

6. Daskal Y, Alfici R, Givon A, Peleg K, Olsha O, Kessel B; Israel Trauma Group. Evaluation of differences in injury patterns according to seat position in trauma victims survived traffic accidents. Chin J Traumatol 2018; 21: 273-276.

7. Chieregato A, Martino C, Pransani V, Nori G, Russo E, Noto A, Simini B. Classification of a traumatic brain injury: the Glasgow Coma scale is not enough. Acta Anaesthesiol Scand 2010; 54: 696-702.

8. Malec JF, Brown AW, Leibson CL, Flaada JT, Mandrekar JN, Diehl NN, Perkins PK. The mayo classification system for traumatic brain injury severity. J Neurotrauma 2007; 24: 1417-1424.

9. Crim JR, Moore K, Brodke D. Clearance of the cervical spine in multitrauma patients: the role of advanced imaging. Semin Ultrasound CT MR 2001; 22: 283-305.

10. Ebtehaj M, Yaqubi S, Seddighi AS, Seddighi A, Yazdi Z. Correlation between BIS and GCS in patients suffering from head injury. Ir J Med Sci 2012; 181: 77-80.

11. Alnaami I, Alshehri S, Alghamdi S, Ogran M, Qasem A, Medawi A, et al. Patterns, Types, and Outcomes of Head Injury in Aseer Region, Kingdom of Saudi Arabia. Neurosci J 2019; 2019: 1-6.

12. Al-Habib A, A-shail A, Alaqeel A, Zamakhshary M, Al-bedah K, AlQunai M, et al. Causes and patterns of adult traumatic head injuries in Saudi Arabia: implications for injury prevention. Ann Saudi Med 2013; 33: 351-355.
Ahoud Alharbi
College of Medicine,
King Saud bin Abdulaziz University for Health Sciences Riyadh, Kingdom of Saudi Arabia 